\title{
CONFLITOS SOCIOAMBIENTAIS DECORRENTES DA CONSTRUÇÃO DAS USINAS DE SANTO ANTÔNIO E DE JIRAU NO RIO MADEIRA
}

\author{
Eduardo Renato Zimmerli \\ Professor na Universidade Federal de Rondônia \\ zimmerli@bol.com.br
}

\begin{abstract}
Osmar Siena
Professor do Programa de Pós Graduação na Universidade Federal de Rondônia osmar_siena@uol.com.br
\end{abstract}

\section{RESUMO}

Este estudo visou caracterizar os principais conflitos socioambientais decorrentes da construção das hidrelétricas de Santo Antônio e Jirau no Rio Madeira. Documentos sobre a temática foram as fontes dos dados e para tratamento foi adotada a análise de conteúdo. Ao todo, foram localizados mais de 600 documentos sobre conflitos socioambientais resultantes da construção das usinas do rio Madeira. Foram selecionados aqueles que continham informações relevantes sobre o estudo proposto, perfazendo um total de 205. Os documentos foram tratados por meio dos softwares Atlas.ti 6 da Scientific Software Development e do Microsoft Excel 2010. Para caracterização dos conflitos foi adotada a abordagem de Paul Little quanto a origem e de Glória Vargas quanto ao tratamento de conflitos. Os principais conflitos identificados foram: Licenciamento; Internacional; Étnico - Indígena; Estrada de Ferro Madeira Mamoré, Bairro Triângulo; Deslocamento Populacional. A principal causa identificada nesses conflitos é a disputa pelo controle dos recursos naturais, sendo utilizada a estratégia de gestão como meio de tratamento. Constatou-se a formação de blocos de resistência, em relação à construção das hidrelétricas, em torno de redes mais experientes e de maior poder de influência. Se não foi conseguido o impedimento das obras, os atingidos pelo Complexo do Rio Madeira aparentemente conseguiram mais avanços que seus pares em relação a eventos similares anteriores.

Palavras-chave: Conflitos socioambientais; Hidrelétricas. Jirau. Santo Antônio.

\section{SOCIO-ENVIRONMENTAL CONFLICTS REGARDING THE CONSTRUCTION OF HYDROELECTRIC POWER STATIONS OF SANTO ANTÔNIO AND JIRAU ON THE MADEIRA RIVER}

\section{ABSTRACT}

This study aims to characterize the main inherent socio-environmental conflicts regarding construction of hydroelectric power stations of Santo Antônio and Jirau on the Madeira River. The data sources were documents regarding the subject and content analysis was the adopted treatment. Altogether, more than 600 documents on the topic have been found and of those, 205 were found to contain relevant information for the study. The documents were further researched and organized using the software Atlas.ti 6 by Scientific Development Software and Microsoft Excel 2010. For conflict characterization, Paul Little's approach was adopted for the origin aspect and Gloria Vargas for the treatment of conflicts. The main identified conflicts were: Licensing; International; Ethnic - Indigenous; Madeira Mamoré Railroad, Triangulo Village, and Population displacement. The dispute for the natural resource control was identified as the main cause for the conflicts. Strategical Management was used as the means of treatment. Resistance blocks towards the hydroelectrical plant construction were detected, supported by more experienced nets with a wider influence of er. If the construction impediment was not obtained, the individuals who were affected by the Madeira River apparently obtained more advances than their peers when compared to previous similar events. Key words: Jirau; Santo Antônio; Sampling; Socio-environmental conflicts. 


\section{INTRODUÇÃO}

Problemas ambientais, apesar de indícios longínquos de seu início (Mebratu, 1998), tiveram incremento de exposição a partir dos anos 1970, resultando na globalização do tema e na inserção de suas questões nas políticas públicas, movimentando a sociedade como um todo. Desta forma, mais e mais pessoas e comunidades têm se inteirado do assunto. Assim, este deixa de estar enclausurado a uma pequena parcela de especialistas. Supostamente, quanto mais indivíduos, instituições e comunidades conhecessem a questão, mais as práticas em defesa do ambiente seriam implantadas. No entanto, Alonso e Costa (2000) coletaram opiniões que não confirmam essa suposição. Nesse contexto, a preocupação de governos e setores da sociedade civil com essa questão e a extensa agenda de discussões ambientais não resultaram em um consenso quanto às soluções apresentadas; pelo contrário, quanto mais as questões foram aprofundadas, mais conflitos eram identificados e mais longe ficaram as soluções preconizadas.

No Brasil, as transformações resultantes deste processo de globalização do tema se manifestaram a partir de uma "[...] política conservadora de ajuste econômico que tem reconduzido meio ambiente e justiça social ao estatuto de 'entraves ao desenvolvimento'." (Zhouri \& Oliveira, 2007, p. 119). Este posicionamento do poder no Brasil propicia campos de confronto entre as populações locais, os empresários e o Estado, cenário evidenciado na política de expansão geração de energia elétrica no Brasil.

A matriz energética brasileira prioriza a elétrica. Durante a primeira Grande Guerra Mundial, entre 1914/1918, e, posteriormente, na reconstrução da Europa nos anos seguintes, a principal fonte energética industrial utilizada no Brasil, o carvão mineral, importado principalmente da Inglaterra e dos Estados Unidos, entrou em crise. Este período coincidiu com o início da geração de energia elétrica incrementada pelo desenvolvimento do café. Até então era também desprezível a importação de petróleo no Brasil, volume que triplicou nos anos seguintes à crise até 1923, quando se estabilizou um crescimento até os anos 1980, coincidindo com o aumento do uso de veículos (Fernandes \& Santos, 2004). Com a posse de Getúlio Vargas, iniciou-se uma fase em que o Brasil obteve grande crescimento de sua economia, alicerçado "[...] na industrialização, na urbanização, na expansão das rodovias, das telecomunicações, da indústria de base." (Fernandes \& Santos, 2004, p. s.p.).

Estes cenários levaram o governo a assumir a geração de energia criando várias empresas estatais a partir dos anos 1940. Nos anos 1950, a inserção do Estado no setor elétrico ficou ainda mais evidente com "[...] a criação da Eletrobrás, e a instituição do Plano Nacional de Eletrificação e a criação do Fundo Federal de Eletrificação." (Fernandes \& Santos, 2004, p. 5). Sendo assim, o governo criou mecanismos de financiamento do setor (Aquino, 2012). Portanto, o governo incentivou a utilização da energia elétrica de forma a obter retorno do volume de capital investido no setor (Fernandes \& Santos, 2004). Com a crise do petróleo na década de 1970 e do gás já neste século houve o reforço na opção pela energia elétrica e pelo processo de geração hidráulico.

Em pronunciamento na inauguração da hidrelétrica de Estreito (17/10/2012), a Presidente Dilma Rousseff reafirmou o entendimento institucional de que prioriza a construção de hidrelétricas, destacando que essa matriz é muito mais adequada do ponto de vista ambiental (Aquino, 2012, p. s.p.). Nesta perspectiva, a gestão de recursos hídricos se insere no contexto do processo político, com ênfase ainda maior quando se trata da Amazônia, embora isto não seja comumente aceito, pois a inclinação atualmente dominante é a de que a política deve ser removida da gestão destes recursos (Mollinga, 2007). Com grande potencial hídrico é sem surpresa que exista a previsão de construção de várias hidrelétricas na região como integrantes do projeto de desenvolvimento do país, entre elas as duas que compõem o chamado Complexo do Rio Madeira: Usina Hidrelétrica (UHE) de Santo Antônio e UHE de Jirau. Neste caso, entre a idealização do projeto, há quase duas décadas, e sua apresentação na Comissão de Minas e Energia da Câmara dos Deputados, em outubro de 2003, houve muita movimentação política. No entanto, foi a partir da Licença Prévia (LP) em julho de 2007, pelo Instituto Brasileiro do Meio Ambiente e dos Recursos

Revista de Gestão Social e Ambiental - RGSA, São Paulo, v. 7, n. 3, p. 89-104, out./dez., 2013. 
Naturais Renováveis (IBAMA), sob forte pressão política e contrariando a posição de seus técnicos, é que se tornaram mais visíveis os conflitos inerentes às obras destes empreendimentos elencados como prioritários pelo governo federal do Brasil. Os impactos sociais e ambientais causaram e ainda causam confrontos entre grupos de interesse diferentes ou divergentes. São confrontos alimentados por altas cifras monetárias e percepções dos afetados.

Este artigo foca estes confrontos, aqui tratados como conflitos socioambientais, e o movimento de grupos sociais que se mobilizaram em torno da defesa de suas posições, neste caso, aqueles inerentes à afetação de suas vidas como cidadãos pela realização de duas grandes construções, as UHE do Jirau e de Santo Antônio no Rio Madeira, no município de Porto Velho/RO. Delimitou-se o campo de estudo aos conflitos socioambientais decorrentes da construção das usinas hidrelétricas. O hiato temporal da pesquisa vai do momento da aprovação das obras em 2005 até março de 2012.

Neste contexto, este estudo partiu de duas das questões deixadas por Alonso e Costa (2000) sobre conflitos socioambientais que tratam sobre as formas de organização e as estruturas de mobilização que os atores envolvidos nas questões socioambientais recorrem e quais são as formas de mediação e arbitragem. Para responder tais indagações, buscou-se caracterizar os principais conflitos socioambientais decorrentes da construção das UHE de Santo Antônio e de Jirau no rio Madeira e as estratégias utilizadas para sua resolução.

Ao realizar levantamento dos principais eventos, as estratégias utilizadas e a identificação dos atores, com a finalidade de classificar estes conflitos, este trabalho possibilita que pesquisas posteriores façam desdobramento do estudo de conflitos específicos surgidos durante as construções, contribuindo assim para a superação das lacunas da literatura brasileira detectadas por Alonso e Costa (2002b), Bredariol (2004) e Vargas (2007).

Este trabalho contém mais quatro partes, além desta introdução. No próximo tópico são discutidos os aspectos teóricos sobre conflitos socioambientais. Na sequência, apresenta-se o método de pesquisa e os procedimentos adotados. No item 4 (quatro) são apresentados e discutidos os principais resultados. Por fim, são elencadas as principais conclusões.

\section{REFERENCIAL TEÓRICO}

Com a visão de política decorrente da separação dos poderes e da constituição de espaços específicos proposta por Montesquieu, é que a partir do século XVII - XVIII, os homens criaram mecanismos de resolução de conflitos, sem que fosse necessária a submissão de uma ou a separação das partes (Nascimento, 2001). Segundo Nascimento (2001), embora estes mecanismos não desprezassem o uso da força, frequentemente a dispensavam, em razão da modificação da noção de conflito que, por sua vez, transformava a natureza da sociedade mercantil. Esta sociedade difere das anteriores em muitos aspectos, inclusive quanto ao entendimento do que é conflito e nos mecanismos de sua resolução, resultando em uma existência de permanente tensão, em inúmeros e constantes conflitos, um dos efeitos da globalização.

Em termos acadêmicos, os conflitos sociais são compreendidos a partir de duas abordagens predominantes, oriundas da Sociologia e da Economia Política (Barbanti Jr., 2002). Uma que atribui às lutas de classe por mudanças socioeconômicas como fonte de conflitos, derivada das ideias marxistas e neomarxistas e outra, que atribui a existência de conflitos à natureza humana, derivada das teorias de Durkheim, subjetivista, abrindo a possibilidade de sua solução à mudança das suas relações (Vargas, 2007; Barbanti Jr., 2002; Pereira; Nascimento, 2010). Estas duas perspectivas excludentes criam uma limitação ao separar condições estruturais e percepções, não reconhecendo que, de forma geral, as duas visões fazem parte do conflito (Vargas, 2007).

Uma abordagem da questão ambiental, na perspectiva de conflitos, está contida nas concepções do movimento por justiça ambiental, uma contraposição à visão hegemônica da modernização ecológica, apontando o caráter desigual de acesso à proteção ambiental (Acselrad, 2002). Nesta visão, Acselrad (2002, p.55) afirma que a “[...] ação coletiva contra a ordem ambiental tida como injusta [...]", manifesta-se em dois planos:

Revista de Gestão Social e Ambiental - RGSA, São Paulo, v. 7, n. 3, p. 89-104, out./dez., 2013. 
[...] no plano da distribuição objetiva dos efeitos ambientais das práticas sociais [...] exprime a diferença de poder sobre os recursos ambientais entre os distintos grupos sociais; [...] no plano discursivo em que vigoram distintos esquemas de representação do mundo, do ambiente, da justiça etc.; neste plano, coloca-se em jogo a legitimidade do modo de distribuição do poder sobre os recursos ambientais (Acselrad, 2002, p. 55).

A partir da "[...] analogia ao procedimento de Pierre Bourdieu na caracterização das condições de existência teórica e prática dos grupos sociais [...]", Acselrad (2002, p.55) denomina esses dois planos, respectivamente, momentos objetivista e subjetivista da análise. Assim, os movimentos sociais podem ser analisados a partir de sua intervenção nesses dois níveis do espaço social: o da distribuição do poder e o da luta discursiva (Acselrad, 2004).

Acselrad (2002) conclui sua análise desses momentos afirmando que: os 'dados' da desigualdade de poder no espaço social já existiam, mas é a luta social que lhes dá visibilidade e contesta sua legitimidade; a força simbólica do movimento de justiça ambiental decorre assim de sua capacidade de estender a matriz dos direitos civis ao campo do meio ambiente, de politizar e unificar uma multiplicidade de embates localizados; e, de elaborar uma "classificação" dos grupos sociais compatível com a posição diferencial reconhecível dos indivíduos no espaço social.

Em outra perspectiva, a partir da dimensão valorativa do ambientalismo, ignora-se a dimensão prática do fenômeno, consequentemente a conceituação da política utilizada para a análise do campo, resultando na redução da questão democrática a um enquadramento estreito, substancialista, intitulado democracia verde; a relação entre democracia e meio ambiente é formulada como inserção de tópicos ambientais nos debates públicos e nas estratégias de grupos organizados. Nesse contexto a qualidade das instituições dependeria do nível de disseminação da "consciência ecológica" entre os atores políticos ou sociais e os atores ambientais no processamento de conflitos ambientais (Alonso \& Costa, 2002b). Desta forma, haveria apenas conflitos ambientais transitórios, pois que, uma vez esclarecidos, os atores passariam às práticas ambientalistas. Assim, a percepção majoritária, tendo como base diversas críticas, é a de que os atuais mecanismos de negociação ambiental são, ainda, incapazes de garantir as condições mínimas para lidar com a questão, pois não há uma abordagem sistêmica dos problemas ambientais que supere a natureza pontual das políticas públicas atuais e um estilo de resolução consensual dos conflitos ambientais capaz de produzir resultados consistentes (Alonso \& Costa, 2000).

Segundo Alonso e Costa (2002b), as câmaras de negociação e modalidades participativas de tomada de decisões para as questões ambientais apenas formalizam os procedimentos para a resolução de impasses, não produzindo uma solução, um consenso. Nestas instâncias, pessoas afetadas julgam a legitimidade das iniciativas segundo sua própria percepção subjetiva das consequências imediatas em sua vida. Nada garante que a participação da comunidade afetada ou dos órgãos de defesa do ambiente resulte em soluções que defendam o ambiente. O que leva a crer que os atores defendem seus interesses egoísticos imediatistas e não as reais questões constantes da utopia dos ambientalistas de outrora. Segundo as autoras, esta perspectiva se apresenta pouco eficaz para responder às questões de governança e de participação impostas. A contaminação entre intérpretes da questão ambiental e militantes ambientalistas promoveu uma evidente vantagem dos sistemas participativos perante os representativos de deliberação. Entretanto, a substituição do método representativo pelo participativo não garante que o funcionamento dos novos formatos institucionais de tomada de decisão em questões ambientais tenha a legitimidade que alardeiam (Alonso \& Costa, 2002b).

Portanto, o reconhecimento de várias visões, abordagens e conceituações sobre ambientalismo e sobre conflitos traz dificuldade para a organização da temática (Vargas, 2007; Zhouri \& Oliveira, 2007), criando obstáculos a mais para o entendimento da questão.

Apesar de várias visões, Alonso e Costa (2000) alertam que a bibliografia a respeito da temática ambiental, de modo geral, se ancora nos conceitos normativos preconcebidos, supondo uma correlação entre a preservação ambiental e participação, desconsiderando outras possibilidades.

Revista de Gestão Social e Ambiental - RGSA, São Paulo, v. 7, n. 3, p. 89-104, out./dez., 2013. 
Recomendam o estudo empírico das instituições político-administrativas dos três poderes no sentido de se verificar se são capazes de solucionar conflitos ambientais e se os mecanismos de governança ambiental influem na definição das políticas públicas da área ambiental. Além disso, o interesse por estudos sobre conflito socioambiental, além de recente, transcende as delimitações de uma única área de conhecimento, constituindo-se em um campo "multi, inter e transdisciplinar" (Barbieri, 2004). Em verdade, a preocupação com os problemas ambientais entrou nas agendas do "[...] establishment político e empresarial capitalista em menos de uma década porque, em síntese, a destruição ambiental compromete a reprodução do capital." (Barbanti Jr., 2002, p. 2). Como resultado, a produção científica a respeito do tema foi incrementada. No levantamento da literatura, constata-se que, embora a temática seja transcendente, há uma quantidade significativa de trabalhos com abordagem na perspectiva legal, uma abordagem sob a ciência do Direito. Apesar deste fato, a questão de conflitos socioambientais está adentrando nas publicações científicas, saindo, portanto, da área agrária para ser tratada, cada vez mais frequentemente, pelas ciências sociais. Assim, deixa de ser uma questão 'apenas' ambiental, tratada pelas áreas de estudo de impactos, migrando para as áreas de geografia social, sociologia, administração, psicologia, entre outras, transcendendo uma única vertente.

Desse modo, a evolução e o desenvolvimento do conhecimento em torno da temática ambiental, em especial no que tange a conflitos socioambientais, têm procurado abordagens que superem as origens distintas deste fenômeno. Neste novo cenário, estudar algo que seja socioambiental exige o diálogo entre os paradigmas que amparam as ciências sociais e aqueles que amparam as ciências naturais, pois não se trata de estudar a dimensão ambiental ou a social separada. Faz-se necessário encontrar uma abordagem que abarque simultaneamente estas dimensões. Desta necessidade, de se lidar com duas dimensões, a social e a biofísica, emergem vertentes com diferentes paradigmas: aqueles que balizam as ciências sociais e aqueles que balizam as ciências naturais. Nas palavras de Muniz (2010, p. 20).

Se a análise social confronta o desafio de incorporar as dinâmicas do mundo biofísico dentro de sua prática, as ciências naturais enfrentam o desafio inverso: no seu entendimento dos distintos ciclos naturais teria que levar em conta o mundo humano e suas estruturas políticas e socioeconômicas.

Nessa perspectiva, consolida-se uma linha teórica denominada de Ecologia Política. Suas características superam estas limitações fronteiriças elencando como foco estudar as relações entre os atores e suas interações. Esta abordagem também se diferencia de outras ao tentar conciliar conceitos com marcos temporais e limitações geográficas distintos, adequados às dimensões estudadas (Little, 2006). De acordo com esta visão, tem-se que conflitos socioambientais são disputas entre grupos sociais em razão de seu relacionamento com a natureza e seus recursos. A partir dessa compreensão, Little (2001) classifica os conflitos socioambientais em três grupos:

- Quanto ao controle de recursos naturais: os recursos naturais são finitos e o controle sobre eles, seja geográfico (político, social ou jurídico) ou tecnológico, é gerador de conflito.

- Quanto aos impactos ambientais e sociais gerados pelas ações antrópicas: conflitos gerados pela intervenção humana, geralmente em torno dos impactos consequentes da contaminação do meio ambiente, do esgotamento de recursos, da degradação de ecossistemas, etc.

- Quanto aos conhecimentos ambientais: conflitos gerados pelo uso dos conhecimentos ambientais, causados quando grupos sociais defendem o controle formal dos conhecimentos ambientais ou quando envolvem lugares sagrados. 
Embora seja muito difícil delimitar rigidamente os conflitos socioambientais nesta tipologia, é possível que se identifique a maior incidência de um dos grupos. Esta caracterização tem como objetivo facilitar a análise dos conflitos a fim de definir as melhores formas de manejo.

Das várias formas de abordagens para manejo de conflitos, entre elas, as socioambientais, Little (2001) delineia cinco tipos básicos de resolução, em uma escala de graduação mais conflituosa a menos conflituosa: de confrontação; de repressão; de manipulação política; de negociação/mediação e; de diálogo/cooperação.

Esta caracterização é mais adequada às abordagens objetivistas, que entendem o conflito na situação político-social e na estrutura da sociedade, pressupondo que o conflito existe independentemente da percepção dos atores. É uma visão em que os ganhos de uma classe significam as perdas de outra (Vargas, 2007).

Outra abordagem é a que entende o conflito como diferença de percepções e objetivos dos atores, frequentemente chamada de subjetivista "[...] que procura as explicações dos conflitos na percepção e incompatibilidade de objetivos entre as partes envolvidas." (Vargas, 2007, p.4). Esta visão oferece maior abertura para discussão sobre negociação de conflitos. Vargas (2007) concorda com uma linha teórica que sintetiza conflitos como consequência de uma ou da combinação possível de: Conflito inserido nos assuntos da sociedade como consequência de percepções; Conflito como uma forma não violenta de adquirir direitos e justiça social; e Conflito como catalizador de mudança social. Esta perspectiva permite o tratamento dos conflitos em três formas:

a) De Gestão: abordagem que entende o conflito como resultado de percepções distintas, de valores e interesses dos atores ou grupos de atores. Subvencionada por uma visão realista da teoria da escolha racional e da teoria dos jogos. Busca de meios "[...] capazes de distribuir as perdas e os ganhos de forma equitativa. Ao se omitirem as causas subjacentes dos conflitos, procuram-se estratégias para atingir situações de ganho para todas as partes.” (2005, p.5). Esta abordagem usa técnicas de mediação e negociação, sendo interessante a participação de terceiros no processo. Outra característica desta abordagem é a de não considerar a eliminação do conflito como essencial ao processo.

b) De Resolução: abordagem que entende o conflito como o resultado de necessidades humanas insatisfeitas. Esta abordagem se baseia na teoria das necessidades humanas se e utiliza da teoria dos jogos na busca de metodologias de resolução. Para Vargas (2007, p.6), a resolução dos conflitos "[...] envolve formas mais processuais que coercitivas, [...] como formas de adensar o nível de comunicação e informação entre as partes.". Mediante a assistência de terceiros, seu objetivo é a busca conjunta de soluções e formas de promoção para a resolução do conflito.

c) De Transformação: abordagem que entende o conflito como uma forma de luta não violenta em busca de justiça social. Lastra-se na teoria dos conflitos, assim considera todo entorno do conflito, suas causas, as mudanças necessárias para sua resolução buscando, ainda, promover ambiente cooperativo. Uma forma em que "[...]grupos marginalizados social ou politicamente podem se mobilizar para dar visibilidade às suas reivindicações e procurar saídas às relações opressivas." (Vargas, 2007, p.6).

Esta última visão pretende superar as limitações das duas abordagens majoritárias, a visão objetivista, que entende o conflito como diferenças estruturais, e a abordagem subjetivista, que compreende conflito como diferenças de percepções e incompatibilidade entre as partes envolvidas.

Este estudo faz uma caracterização de origem dos conflitos se utilizando das justificativas da abordagem objetivista, com maior potencial para aplicação em termos empíricos e classifica a manipulação segundo a proposta mais abrangente de Vargas, aqui chamada de alternativa. Isto é possível se se partir do tratamento objetivista de 'Negociação/Mediação' ou de 'Diálogo/Cooperação'. Na figura 1 são apresentados os elementos das abordagens sobre conflitos socioambientais.

Revista de Gestão Social e Ambiental - RGSA, São Paulo, v. 7, n. 3, p. 89-104, out./dez., 2013. 


\begin{tabular}{|c|c|c|c|}
\hline & $\begin{array}{c}\text { Conceito de conflitos } \\
\text { socioambientais }\end{array}$ & $\begin{array}{c}\text { Caracterização da origem de } \\
\text { conflitos }\end{array}$ & Formas de manipulação \\
\hline \multirow{3}{*}{$\begin{array}{l}\text { Abordagem } \\
\text { objetivista }\end{array}$} & \multirow{3}{*}{$\begin{array}{l}\text { Disputas entre grupos sociais, em } \\
\text { razão de seu relacionamento com a } \\
\text { natureza e seus recursos. }\end{array}$} & $\begin{array}{l}\text { Quanto ao controle de recursos } \\
\text { naturais }\end{array}$ & \multirow{3}{*}{$\begin{array}{l}\text { Confrontação } \\
\text { Repressão } \\
\text { Manipulação política } \\
\text { Negociação/Mediação } \\
\text { Diálogo/Cooperação }\end{array}$} \\
\hline & & $\begin{array}{l}\text { Quanto aos impactos ambientais e } \\
\text { sociais gerados pelas ações antrópicas }\end{array}$ & \\
\hline & & Quanto aos conhecimentos ambientais & \\
\hline $\begin{array}{l}\text { Abordagem } \\
\text { subjetivista }\end{array}$ & $\begin{array}{l}\text { Conflito como diferença de } \\
\text { percepções e objetivos dos atores }\end{array}$ & Percepções & \\
\hline \multirow{3}{*}{$\begin{array}{l}\text { Abordagem } \\
\text { alternativa }\end{array}$} & $\begin{array}{l}\text { Conflito inserido nos assuntos da } \\
\text { sociedade como consequência de } \\
\text { percepções }\end{array}$ & \multirow{3}{*}{ Percepções } & \multirow{3}{*}{$\begin{array}{l}\text { Gestão } \\
\text { Resolução } \\
\text { Transformação }\end{array}$} \\
\hline & $\begin{array}{l}\text { Conflito como uma forma não } \\
\text { violenta de adquirir direitos e justiça } \\
\text { social }\end{array}$ & & \\
\hline & $\begin{array}{l}\text { Conflito como catalizador de } \\
\text { mudança social. }\end{array}$ & & \\
\hline
\end{tabular}

Figura 1: Abordagem de conflitos socioambientais

Fonte: Elaborado pelos autores

Para identificar os participantes dos conflitos, este artigo adota a designação 'atores' com o sentido definido por Dubar (2004), em que o ator é o sujeito de uma ação, racional, autônomo, municiado de vontade própria, capaz de escolhas e de manipulação, não apenas se adaptando, mas se aproveitando das oportunidades disponíveis.

Para Nascimento "[...] todo conflito reúne um conjunto de atores que se posicionam e se dispõem diferentemente entre si, articulam-se ou se opõem. [...] Nunca estão estáticos, e nem sempre perceptíveis em seus movimentos." (2001, p. 95). O referido autor defende que "Os atores podem ser definidos como indivíduos, grupos ou organizações de identidade própria, reconhecidos por outros, com capacidade de modificar seu ambiente de atuação." (2001, p. 95).

Evidentemente, os atores mudam segundo a natureza dos conflitos, se são de ordem econômica, administrativa, ideológica, enfim, para cada caso há atores diferentes.

\section{MÉTODO E PROCEDIMENTOS METODOLÓGICOS}

Esta pesquisa se baseia na concepção que defende que os indivíduos desenvolvem significados de suas experiências (Creswell, 2010). Fenomenológico, qualitativo, partiu do pressuposto de que o mundo social é relativista, portanto, entendido a partir da compreensão dos indivíduos envolvidos nas situações estudadas (Vergara, 2005). Com o intento de expor as características dos fenômenos se utilizou, majoritariamente, das técnicas da pesquisa documental com análise de conteúdo.

Considerou-se, neste estudo, que os conflitos são passíveis de manejo (Vargas, 2007), utilizando um roteiro inicial convencional aos manuais de mediação: caracterização macro das questões ambientais do evento, identificação dos atores e as instâncias de negociação.

Devido à envergadura das obras no rio Madeira, foram produzidos trabalhos científicos, relatórios de atores, informes nas mídias, impressa e audiovisual, documentos públicos dos atores de forma geral, como manifestos, cartas e fotografias, além de documentos oficiais, tais como o Estudo de Impactos Ambientais Ambiente (EIA), o Relatório dos Impactos ao Meio Ambiente (Rima), atas de reuniões, atas das audiências públicas e outros relatórios. Este acervo, aceito após pré-análise de sua autenticidade, representatividade, credibilidade e significação (Scott apud Flick, 2009), constituiu a fonte de dados. Foram localizados mais de 600 documentos sobre conflitos socioambientais decorrentes da construção das usinas do Rio Madeira e foram selecionados aqueles que continham informações relevantes sobre o estudo proposto, perfazendo um total de 205 . Os principais autores destes documentos são: Ministério Público Estadual e Federal, IBAMA, Assembleia Legislativa do Estado de Rondônia, Câmara dos Deputados, Secretaria de Estado do 
Desenvolvimento Ambiental (Sedam/RO), a Fundação Nacional do Índio (Funai), pesquisadores, organizações não-governamentais envolvidas e jornais impressos e eletrônicos.

Os documentos foram tratados por meio dos softwares Atlas.ti 6 da Scientific Software Development, utilizados como ferramentas de apoio para localização e organização das informações, e do Microsoft Excel 2010 de forma a organizar os resultados. Após a identificação dos atores nos documentos preliminares, chegou-se a um número superior a 250 atores, desta forma, por terem características similares, foram agrupados em 52 grupos distintos considerando-se suas peculiaridades.

Identificados os autores, foi iniciada uma busca eletrônica utilizando-se como palavraschave o nome dos atores, suas características e movimentações, bem como os processos e os impactos ambientais identificados no processo inicial. Desta busca, foi executada outra análise com o intuito de identificar os conflitos macropleiteados neste estudo.

Quanto à origem, os conflitos foram caracterizados em três categorias seguindo o arcabouço proposto por Little (2001): conflitos originados por questões de controle dos recursos naturais; conflitos gerados a partir de impactos ambientais causados por ações antrópicas; e conflitos causados por desnível de conhecimentos ambientais.

Quanto à abordagem estratégica ou o tratamento de conflito adotado no estudo, foram distinguidos, conforme Vargas (2007), aqueles em que se utilizaram a: gestão do conflito; resolução do conflito; ou transformação do conflito. Na Figura 2 é apresentado o esquema utilizado.

\begin{tabular}{|c|c|c|c|c|c|c|}
\hline \multirow{3}{*}{ Conflito } & \multicolumn{3}{|c|}{ Origem dos conflitos } & \multicolumn{3}{c|}{ Estratégia de tratamento do conflito } \\
\cline { 2 - 6 } & $\begin{array}{c}\text { Controle dos } \\
\text { recursos } \\
\text { naturais }\end{array}$ & $\begin{array}{c}\text { Impactos gerados } \\
\text { por ações } \\
\text { antrópicas }\end{array}$ & $\begin{array}{c}\text { Conhecimentos } \\
\text { ambientais }\end{array}$ & Gestão & Resolução & Transformação \\
\hline
\end{tabular}

Figura 2: Esquema de caracterização dos conflitos socioambientais

Fonte: Adaptação de Little (2001); Vargas (2007) e Nascimento (2001).

Identificados os conflitos, estes foram descritos de forma sumária, indicadas as ocorrências das movimentações mais significativas dos atores. Este arcabouço permitiu o preenchimento dos dados objetivados, quais sejam: identificar os atores, caracterizar os conflitos socioambientais segundo suas propriedades, o tratamento utilizado para sua resolução e seu status quo em março de 2012.

\section{RESULTADOS E DISCUSSÃO}

Um empreendimento de envergadura, como a construção de uma hidroelétrica, necessita cumprir um processo designado de Licenciamento que tem um ritual complexo e de difícil compreensão para leigos. Há, nesse processo, envolvimento de diversas agências e outras instituições governamentais, o que significa uma diversidade de interesses. Este processo se inicia com a autorização do Estudo de Inventário do campo a ser afetado, a análise dos impactos sociais e ambientais, os programas de mitigação e de compensação desses impactos consequentes das ações antrópicas, sejam antes, durante ou depois destas e finalmente as licenças.

$\mathrm{O}$ arcabouço institucional permite que sociedade se una em defesa de "[...] um direito fundamental coletivo - o meio ambiente ecologicamente equilibrado." (Benites \& Maganhini, 2011, p.3). $\mathrm{O}$ arcabouço institucional permite que sociedade se una em defesa de "[...] um direito fundamental coletivo - o meio ambiente ecologicamente equilibrado." (Benites \& Maganhini, 2011, p.3). A sociedade se manifesta a partir dos seus atores. Estes atores são oriundos de diversos espaços e interesses sociais - famílias diretamente afetadas pelo impacto ambiental negativo, ambientalistas, pesquisadores, instituições acadêmicas, sindicatos, associações, organizações nãogovernamentais, entidades ecumênicas - e se manifestaram em forma de campanhas, movimentos, fóruns, monções e cartas abertas. A quantidade significativa destes atores nos remete à inserção do tema no cotidiano da sociedade. 
De acordo com a análise preliminar dos documentos selecionados para pesquisa, foram identificados seis principais conflitos envolvendo a construção das usinas no Rio Madeira: Conflito do Licenciamento; Conflito Internacional; Conflito Étnico: Indígenas; Conflito da Estada de Ferro Madeira Mamoré (EFMM); Conflito do Bairro Triângulo e Conflito do Deslocamento da População Afetada.

Embora o projeto para construção do Complexo do rio Madeira tenha se iniciado em 2003, foi em dezembro de 2005, com a apresentação dos estudos preliminares, que a sociedade acabou por ter acesso às informações neles contidas e a partir daí, seja pela sociedade que entendeu a realidade da obra, seja pela conscientização dos mais diretamente afetados, os atores se movimentaram mais expressivamente. Aqueles com menor representatividade acabaram por se agregar às organizações mais experientes nessas questões, tais como o Movimento dos Atingidos por Barragens (MAB), Amigos da Terra, Rede Rios Vivos, que têm ligações internacionais; organizações confessionais como o Conselho Indígena Missionário (CIMI) e a Comissão Pastoral da Terra (CPT), ligadas à Conferência Nacional dos Bispos do Brasil (CNBB), também com experiência e apoio internacional; e, indiretamente, instituições acadêmicas, a partir de seus pesquisadores.

Assim, em 2006, vários atores iniciaram sua organização planejada de modo a elaborar uma frente de veto à construção das usinas, culminando com o lançamento da campanha Viva o Rio Madeira Vivo, por meio da divulgação da 'Cartilha Viva o Rio Madeira Vivo, diga não às usinas do Madeira'. A esta campanha se agregaram muitos movimentos unindo várias representações, todos envidando o veto das obras, mobilizações estas que se arrefeceram quando da emissão da Licença de Provisória (LP) e mais ainda quando da emissão da Licença de Instalação (LI), evidenciando que o posicionamento dos atores opositores era de veto e não tinham outras reinvindicações. Após a emissão da LP até a LI a movimentação se concentrou em reverter a decisão já adotada.

Se até meados de março de 2007 a movimentação explícita dos atores a favor do empreendimento foi muito discreta, muda a partir dai, quando já corriam boatos da possibilidade de uma postergação à LI. Quase que em uníssono, as movimentações destes atores se tornaram públicas a partir de plenárias nas instâncias legislativas, tendo como linha de justificativa o impedimento de outro episódio de 'apagão', geração de emprego e crescimento econômico. Na Prefeitura Municipal de Porto Velho nasceu, junto com entidades empresariais e sindicatos, um movimento pró-construção das usinas. Estes atores e todos os interessados nas obras tiveram um revés com a publicação do parecer da Diretoria de Licenciamento do IBAMA sustentando a inviabilidade ambiental das usinas, portanto uma decisão desfavorável à concretização do empreendimento. Foi uma convulsão em nível nacional, culminando com a destituição de técnicos que assinam o parecer, a mudança da direção e a divisão do órgão dois meses depois. Essa movimentação do governo, engrossada pela mídia, caricaturou os grupos desinteressados na efetivação do empreendimento como obstrutores do desenvolvimento. Em favor da construção, deflagrou-se a Campanha Usinas Já, com caravanas, carreatas e montagem de equipes volantes com a missão de arrecadar assinaturas de apoio. Este movimento contou com o apoio político das prefeituras e do Estado.

Como reação, os atores não interessados na construção realizaram uma série de movimentos denunciando um clima de intimidação e uso da máquina pública. Pesquisadores promoveram debates públicos, estes boicotados pelos apoiadores das obras. Neste período, os posicionamentos se tornaram mais agressivos e as ações legais se intensificaram. Este embate permaneceu até a concessão da LP para a UHE de Santo Antônio, do Leilão e da LI. Este cenário se manteve em relação às etapas formais para o início das obras da UHE de Jirau, com movimentos intensos e acirrados em forma de denúncias e ações públicas, contra as Agências, a União e as empreiteiras. A mudança de eixo da UHE de Jirau anunciada após o Leilão gerou reações também dos concorrentes que tiveram seus lances superados no leilão. Portanto, a posição dos atores nesta fase do fenômeno foi claramente de veto ou de promoção (Vargas, 2007). 
Apesar das restrições apontadas as licenças foram concedidas, o que corrobora as posições expostas por Zhouri e Oliveira (2007) à respeito dos conflitos sociais em torno da construção de usinas hidrelétricas: a política conservadora no aspecto econômico tem reconduzido tanto o meio ambiente quanto a justiça social ao estatuto de 'entraves ao desenvolvimento' e, citando Esteva (1992, p.119), os autores afirmam que as transformações no Brasil, resultado deste processo de globalização, de maneira geral, se manifestaram a partir de valores econômicos que exigem "[...] a desvalorização de todas as outras formas de vida social.".

Durante o processo de licenciamento, provocado por denúncias de ONGs que contestaram e descreveram as falhas no processo de licenciamento das UHEs Santo Antônio e Jirau, o Ministério Público Estadual e o Ministério Público Federal entraram com uma ação Civil Pública Ambiental contra a Agência Nacional de Energia Elétrica (Aneel), IBAMA e a empreiteira (em 2008), pleiteando a anulação do leilão e do contrato de concessão, em razão da mudança do eixo da obra, por contrariar o edital do leilão e a legislação ambiental. Por outro lado, a mobilização dos opositores à implantação da UHEs foi mais intensa e ativa em seu início, quando da movimentação em torno do impedimento das obras. Nesta fase foram organizadas grandes mobilizações, tanto em defesa quanto favoráveis ao veto da construção das UHEs. Os recursos de promotores e de opositores foram envidados de forma a mobilizar a sociedade. A origem desse conflito, do controle dos recursos minerais, ficou explícita, em razão da posição de veto dos opositores ter sido majoritária e declaradamente alicerçada na defesa dos recursos ambientais. De acordo com a tipologia de Vargas (2007), não houve abordagem de tratamento de resolução ou transformação, mas de gestão do conflito.

Em dezembro de 2008 ocorreu o primeiro grande desastre ambiental no qual morreram 11 toneladas de peixes que, segundo laudo do IBAMA, ocorreu em decorrência da queda de nível de oxigênio nas águas, constatando negligência e imprudência. Como decorrência foi lavrada multa de $\mathrm{R}$ \$ 7,7 milhões. Tal fato que foi encampado como mais um argumento ambiental contra as obras.

Durante esse processo não se vislumbrou nenhum vestígio do exercício do modelo de governança para questões de gestão de recursos hídricos, proposta a partir da Conferência Internacional sobre Água e Meio Ambiente, realizada em Dublin, em 1992 e adotado a partir da Conferência Rio-92, que defende os princípios da 'boa' governança - transparência, equidade, legitimidade, responsabilidade, monitoramento e auditoria, entre outros - para garantir a interação e permitir o trade of entre os grupos com eficácia, incrementando as soluções de consenso (Turton et al., 2007). No caso em estudo, este fato contribuiu de forma decisiva para o surgimento dos conflitos.

Na Figura 3 são sintetizados os resultados sobre a origem e o tratamento dos conflitos para o conflito do licenciamento e para os demais conflitos identificados. 


\begin{tabular}{|c|c|c|c|}
\hline \multirow[b]{2}{*}{ Conflito } & \multicolumn{3}{|c|}{ Origem dos Conflitos } \\
\hline & $\begin{array}{c}\text { Controle dos recursos } \\
\text { naturais }\end{array}$ & $\begin{array}{c}\text { Impactos por ações } \\
\text { antrópicas }\end{array}$ & $\begin{array}{c}\text { Conhecimento } \\
\text { ambiental }\end{array}$ \\
\hline \multicolumn{4}{|l|}{ Licenciamento } \\
\hline \multicolumn{4}{|l|}{ Internacional } \\
\hline \multicolumn{4}{|l|}{ Étnico: Indígenas } \\
\hline \multicolumn{4}{|c|}{ Estrada de Ferro Madeira Mamoré EFMM } \\
\hline \multicolumn{4}{|l|}{ Bairro Triângulo } \\
\hline \multicolumn{4}{|l|}{ Deslocamento da população afetada } \\
\hline \multirow{2}{*}{ Conflito } & \multicolumn{3}{|c|}{ Estratégia de tratamento do conflito } \\
\hline & Gestão & Resolução & Transformação \\
\hline \multicolumn{4}{|l|}{ Licenciamento } \\
\hline \multicolumn{4}{|l|}{ Internacional } \\
\hline \multicolumn{4}{|l|}{ Étnico: Indígenas } \\
\hline \multicolumn{4}{|c|}{ Estrada de Ferro Madeira Mamoré EFMM } \\
\hline \multicolumn{4}{|l|}{ Bairro Triângulo } \\
\hline Deslocamento da população afetada & & & \\
\hline
\end{tabular}

Figura 3: Origens e estratégias de tratamento dos conflitos

Fonte: Elaborado pelos autores

O Conflito Internacional ocorre em paralelo com o Conflito do Licenciamento. As ONGs bolivianas e peruanas, contrárias à construção das usinas, se uniram com os grupos brasileiros, participaram dos movimentos brasileiros, promoveram outros em suas pátrias e assinam cartas abertas. Há também manifestações oficiais entre estes governos. Findando 2006, organizações campesinas e ambientalistas publicaram em Riberalta o Pronunciamiento de la Región Amazónica de Bolivia en torno a las represas proyectadas sobre el río Madera, a Aliança Social Continental e o Movimento Boliviano para a Soberania, alertando sobre a possibilidade de impactos ambientais em território boliviano. Exigem que o governo boliviano interceda junto ao governo brasileiro e às Organizações Multilaterais quanto aos possíveis danos e que incluam os afetados bolivianos nas discussões a respeito do projeto. Desta forma, David Choquehuanca, do Ministerio de Relaciones y Cultos, envia carta para Celso Amorim, do Ministério das Relações Exteriores do Brasil, solicitando uma comissão binacional para tratar da análise de projetos relativos ao rio Madeira.

Várias outras ações foram desencadeadas tanto pela sociedade, inclusive com reuniões de representantes de ribeirinhos e campesinos bolivianos, quanto pelo governo boliviano. No entanto, o governo brasileiro responde dizendo que as obras estão integralmente em território brasileiro e seu licenciamento é de responsabilidade das autoridades ambientais brasileiras; não há o reconhecimento de que a formação de um recurso hídrico em geral, como no caso do rio Madeira, transcende as fronteiras geográficas e sua utilização deve incorporar o conceito de gestão integrada, que supera a visão tradicional de que este tipo de questão se restringe a um problema de engenharia que envolve apenas a oferta e demanda (Turton et al., 2007). A notícia no periódico O Globo exemplifica essa posição: "Usinas: país não aceitará intervenção boliviana.", apesar de diversas manifestações de autoridades do conhecimento contradizendo esse posicionamento. Enfim, a Bolívia foi tomada pelo posicionamento hegemônico do Brasil, a exemplo do que já foi feito com o Paraguai em outros tempos, uma vez que autoritariamente o país define o desenvolvimento de grandes empreendimentos sem os devidos cuidados aos direitos de seus vizinhos.

De modo semelhante ao ocorrido no Brasil, a população atingida não teve apoio das regiões mais desenvolvidas da República Boliviana. Note-se que a região afetada é a região mais pobre da Bolívia e que os demais são relativamente indiferentes com o que ocorre nessa região, povoada por nativos, em sua maioria de etnias diversas dos centros mais desenvolvidos.

Revista de Gestão Social e Ambiental - RGSA, São Paulo, v. 7, n. 3, p. 89-104, out./dez., 2013. 
Assim, pode-se afirmar que, pelo lado brasileiro, o conflito internacional com envolvimento da Bolívia e do Peru foi causado em razão do domínio dos recursos e, em termos de tratamento, foi abordado como gestão do conflito, no entanto sem exercício das ferramentas possíveis de utilização, dada a extrema desvantagem em termos de poder entre os atores envolvidos, no caso Brasil e Bolívia predominantemente. O governo boliviano ficou ambíguo entre defender o meio ambiente, como tentou o ministério inerente e o favorável, como o setor energético e de transportes. Aqui vale anotar que os estudos da hidrovia estão avançados no território boliviano e peruano, um empreendimento ao qual o Brasil se posiciona como tendo recuado de seu intento. Ainda neste sentido é dicotômica a posição do Presidente Evo Morales, que inicialmente se posicionou contra os empreendimentos e depois se calou, contrariando as solicitações da Via Campesina, organização da qual é membro fundador.

Outro conflito identificado é o Étnico: Indígenas, com origem nos possíveis impactos das usinas em suas, em especial alterações nos cursos d'agua. Apesar dos estudos indicarem que os empreendimentos não atingiriam as comunidades, pois estas não margeiam o rio Madeira, representantes dos indígenas alegaram que elas seriam diretamente atingidas pelas alterações que seriam provocadas nos igarapés, afluentes do rio Madeira, que banham suas terras.

Vale ressaltar que o Brasil é signatário da Organização das Nações Unidas (ONU), da Organização dos Estados Americanos (OEA), da Organização Internacional do Trabalho (OIT), entre outras organizações de defesa dos direitos humanos. Pode parecer redundante, mas estes foram os destinatários das reivindicações dos atores defensores das minorias indígenas e quilombolas, embora esta última apareça muito discretamente como apoiadora em movimentações indígenas. Além disso, o Brasil é regido por sua Constituição Federal e, no caso, argui-se o não acatamento do seu artigo $5^{\circ}$ que versa sobre os direitos do cidadão, linha em que se baseia a maioria das argumentações utilizadas. A Fundação Nacional do Índio (Funai) não se opôs aos licenciamentos das obras, ainda que tenha anuído ter conhecimento e ser denunciante da incompletude dos estudos iniciais em relação aos povos indígenas.

Outra característica neste conflito é que, por natureza, estas minorias, a indígena e quilombola, optam pelo isolamento ou são isoladas e, assim, ficam à mercê dos acontecimentos por ausência. Esta é a razão de serem estes atores representados por outros voluntariamente, tais como a ONG Kanindé, o Conselho Indigenista Missionário (CIMI), a Coordenação das Organizações Indígenas da Amazônia Brasileira (Coiab) e os institucionalizados, como a própria Funai. A diferença é que os institucionalizados são investidos de poder e ganham para isto, sendo uma função remunerada, independentemente de ser voluntária ou voluntariosa. Os movimentos de oposição e vistos pela sociedade não contavam com povos indígenas mais isolados. Os índios que participaram dos eventos são índios com mais informação, com maior interação com a civilização colonizadora, como os Cinta Larga, os Gaviões, os Araras e os Karitiana, unidos em defesa de suas origens. Após o Licenciamento, as ONGs Kanindé, Cimi, Coiab e outras que defendem minorias étnicas, se uniram nas manifestações sociais programadas por outros grupos, tais como o MAB, Amigos da Terra e Via Campesina. Concomitantemente, se valeram de ferramentas para alcançar as vias internacionais, tais como a Organização das Nações Unidas (ONU), a Organização dos Estados Americanos (OEA) e o Tribunal das Águas, em forma de denúncias argumentando a desconsideração dos estudos quanto às populações tradicionais. Apesar de diligências e inspeções destas organizações, houve pouca alteração no cenário.

Desta forma, este conflito se desenhou de forma diferente dos demais, pois o sentido de propriedade não pode ser definido para os povos isolados que têm por hábito evitar as populações e aglomerados, o que causa seu deslocamento compulsório criando conflitos outros que não são objeto deste estudo. Elimina-se a causa do conflito por ações antrópicas, uma vez que este se desenha desde antes que estas ações aconteçam. Assim, este conflito poderia ser visto, na definição de Little (2001), como causado por diferenças culturais, ou seja, aqui descrito como desnível de conhecimento, mas uma limitação deste raciocínio é que para haver desnível deve haver comparação e o conhecimento dos povos tradicionais não se compara com outros conhecimentos.

Revista de Gestão Social e Ambiental - RGSA, São Paulo, v. 7, n. 3, p. 89-104, out./dez., 2013. 
No entanto, os defensores das minorias étnicas, indígenas e quilombolas, tomam uma posição de veto, na tentativa de impedir a afetação a estes povos, o que remete à disputa do direito de domínio dos recursos. Por isso, considerando a tipologia adotada (Little, 2001), assume-se a principal causa como uma disputa por recursos naturais, pois não foi possível associá-lo a outro tipo. Seu tratamento é de gestão de conflito e, como nos casos anteriores, prevaleceu o uso da teoria dos jogos, forçando um resultado de soma zero, não sendo aplicada, na medida do possível, a teoria da escolha racional.

O conflito identificado como Conflito da Estrada de Ferro Madeira Mamoré (EFMM) se constitui pela preservação do patrimônio cultural tombado em 1989 pela Constituição do Estado de Rondônia e em 2005 pelo Instituto do Patrimônio Histórico e Artístico Nacional (Iphan). Com as obras e o alagamento das represas do Complexo do Madeira, muitas partes da antiga EFMM ficarão comprometidas, submersas ou descaracterizadas. Apesar dos impactos previstos, o Iphan anui com o conteúdo dos EIA/Rima, apenas impõe condicionantes, solicitando a apresentação de projeto de diagnóstico arqueológico. Em documento institucional informa sobre medidas de compensação e não em ações mitigadoras. Em posição diversa, a Associação de Preservação do Patrimônio Histórico do Estado de Rondônia de Amigos da Madeira-Mamoré (AMMA), descreve uma série de acontecimentos em carta denúncia enviada ao Ministro de Cultura. Por sua vez, a Comissão Parlamentar de Inquérito (CPI) das Usinas da Assembleia legislativa (ALE) confirma haverem documentos que demonstram danos aos bens e acervos da Estrada de Ferro. Durante a Diligência da Câmara dos Deputados, em março de 2012, consta depoimento, documentos e fotos que apontam a total desconsideração pela histórica Estrada de Ferro. Apesar destes fatos, a solução adotada foi desenvolver um conjunto de medidas compensatórias, como, por exemplo, a restauração de prédios e máquinas. Assim, este conflito pode ser classificado como originário das ações antrópicas e a abordagem de tratamento foi o de gestão (Vargas, 2007).

O bairro do Triângulo, um dos mais antigos da cidade, localizado bem próximo da jusante da barragem, mais de um século depois de seu início, será remodelado, pois a força das águas derrubou uma série de construções mais próximas da margem, desalojando as famílias ali residentes. Esse fenômeno é decorrente da alteração da mecânica original do rio Madeira, em consequência da abertura das primeiras comportas da UHE de Santo Antônio que se iniciou em dezembro de 2011. Por isso, este conflito é causado por ações antrópicas.

É interessante colocar que esta foi uma ocorrência não prevista nos estudos iniciais do complexo, corroborando com as insistentes denúncias de incompletude de tais estudos, bem como reforça a percepção de que os atuais mecanismos de negociação ambiental são, ainda, incapazes de garantir as condições mínimas para lidar com a questão, pois não há uma abordagem sistêmica dos problemas ambientais que supere a natureza pontual das políticas públicas atuais e um estilo de resolução consensual dos conflitos ambientais capaz de produzir resultados consistentes (Alonso \& Costa, 2000), visto que as ações, antes de iniciar os empreendimentos, não são capazes de prever todos os impactos.

Uma vez caracterizado o conflito como resultado de ações antrópicas, tentou-se um tratamento de gestão, visto que a empresa construtora buscou, num primeiro momento, se isentar do problema, mas com a interveniência do MP, resultou em um tratamento com abordagem de Resolução do conflito, embora não se possa eliminar a causa em si, os afetados foram afastados da causa, e atendidas suas necessidades materiais. Enfim, é um tratamento processual, não coercitivo que trará outros conflitos sociais decorrentes das perdas culturais dos afetados. Por último, o conflito do deslocamento da população afetada deveria ter seu início após a realização do leilão, quando o então ganhador da concessão seria conhecido.

Por último, o conflito do deslocamento da população afetada deveria ter seu início após a realização do leilão, quando o então ganhador da concessão seria conhecido. No entanto, há documentação da abordagem do consórcio ganhador junto aos ribeirinhos e colonos desde antes da promulgação do resultado do leilão, o que remete a uma dúvida quanto à transparência do processo.

Revista de Gestão Social e Ambiental - RGSA, São Paulo, v. 7, n. 3, p. 89-104, out./dez., 2013. 
A população atingida se compõe de assentados do Instituto Nacional de Colonização e Reforma Agrária (Incra) e de ribeirinhos moradores das margens do rio, inclusive de núcleos urbanos, e deveria ser protegida pelas condicionantes da LP, que exigia a apresentação de medidas mitigadoras às famílias não proprietárias na área de influência dos empreendimentos e a consideração de medidas de apoio aos assentamentos de reforma agrária, agricultores familiares e comunidades ribeirinhas na área de influência do empreendimento no Programa de Compensação Social, visando ao desenvolvimento de atividades ambientais sustentáveis.

O programa de remanejamento da população atingida de um dos empreendimentos está subdividido em dois subprogramas: o Subprograma de Remanejamento da População Atingida e Subprograma de Reorganização das Atividades Produtivas. No caso do primeiro, a delimitação do número de pessoas a serem reassentadas tem um equívoco em relação às pessoas a serem compensadas, uma vez que considera apenas aquelas pessoas que vivem na área até 100 metros da margem do rio, em flagrante violação legal, que exige a criação de uma Área de Proteção Permanente (APP) de 500 metros para rios com larguras superiores a 600 metros, caso do Rio Madeira. Isto também provoca um censo muito diferente que aquele levantado no programa, o que explica a diferença significativa entre o levantamento do consórcio e das organizações nãogovernamentais. No caso da UHE Jirau, com a criação de uma vila para deslocamento de toda população, o empreendedor não atendeu a solicitação de considerar a estrutura familiar de todos os afetados, independentemente de serem ou não proprietários legais dos imóveis. Desta forma, planejou as moradias destas pessoas à semelhança do Projeto Minha Casa Minha Vida, do Governo Federal, alegando que os assentados poderiam posteriormente implementar melhorias em suas moradias. A adaptação do povo a esses reassentamentos não ocorreu como esperado, tendo os afetados estranhado o novo local e a alteração dos costumes. Há, ainda, denúncias de infraestrutura precária e de construção deficiente das moradias. Outro ponto negativo é o insucesso na implantação dos projetos econômico-produtivos alternativos. Este conflito está muito longe de seu fim e a tendência é de se agravar à medida que o lago for enchendo e que se tome conhecimento dos impactos não estudados ou não divulgados. As ONGs se respaldam nos dados históricos, nos casos em que hoje, mais de 20 anos após o desassentamento, a população atingida ainda espera a definição e a indenização do ocorrido.

O conflito fica então definido como tendo por origem a ação antrópica de barragens no Rio Madeira, deslocando povoamentos, núcleos urbanos e rurais para fora da área de alagamento da represa. O tratamento dado é de resolução, uma vez que ao serem atendidas as necessidades humanas insatisfeitas o conflito se extingue.

\section{CONSIDERAÇÕES FINAIS E SUGESTÕES}

A ineficácia histórica das ações anteriores em defesa de minorias fez com que os grupos de atingidos pela construção de usinas hidroelétricas do rio Madeira adotassem novos formatos de movimentação. Neste estudo constatou-se a formação de blocos de resistência em relação à construção, em torno de redes mais experientes e de maior poder de influência. Se não foi conseguido o impedimento das obras, os atingidos pelo Complexo do rio Madeira aparentemente conseguiram mais resultados que seus pares no caso da usina de Samuel no Rio Jamari, afluente do rio Madeira, concluída ainda na década de 1980, até hoje sem definição das indenizações.

A causa mais premente dos conflitos identificados foi pelo controle dos recursos naturais, uma vez que se a obra não fosse executada, nenhum desses problemas aconteceria.

$\mathrm{Na}$ fase inicial houve consenso dos atores opositores às obras, caracterizado pela posição de veto. Após o insucesso do impedimento das obras, com as concessões das licenças, os atores se dispersaram em interesses individualizados a partir de percepções e causas diferentes, inclusive nos casos de defesa do patrimônio cultural no conflito da EFMM e das minorias étnicas.

No caso do deslocamento da população, uma vez que foi desestabilizada uma situação consolidada, ou seja, das moradias e urbanidades, causando a supressão de necessidades humanas

Revista de Gestão Social e Ambiental - RGSA, São Paulo, v. 7, n. 3, p. 89-104, out./dez., 2013. 
básicas já satisfeitas, foi criado outro conflito em busca da reparação do que foi e é percebido como injustiça social.

Embora os Ministérios Públicos, Federal e Estadual, tenham se movimentado em todos os conflitos, tiveram êxito parcial, uma vez que as decisões de suas ações tiveram uma média de resposta final superior a mil dias, ou seja, quando já eram irreversíveis os acontecimentos.

As decisões foram estritamente políticas, impositivas, não condizentes com uma democracia e em total retrocesso às conquistas legais em termos de defesa do meio ambiente que o Brasil conseguiu desde o evento da Rio 92 e, em especial, revelando total desprezo aos princípios da 'boa' governança firmados na Conferência Internacional sobre Água e Meio Ambiente, realizada em Dublin.

Os impactos foram e são de grande vulto e é de se estranhar que uma plêiade de estudiosos tenha soluções alternativas tão ou mais eficientes que as decididas na cúpula governamental, que se arvora da autoridade e omissão de informações para vender um eldorado que, historicamente, não se concretiza. Note-se que o planejamento energético brasileiro vem dos anos 1950 e não foi adaptado para atender os avanços da legislação ambiental.

O tratamento dos conflitos causados pelo empreendimento partiu sempre do conforto da hegemonia dos promotores do evento frente aos atingidos, com uma disparidade de poder e uma correlação de forças desproporcional. O comportamento adotado pelos gestores do processo dá sempre a impressão que já conhecessem o resultado, pois partem do posicionamento de fato consumado. Isto traz pouco avanço à democracia exigida pela sustentabilidade, uma vez que o preço é pago por aqueles quase indefesos. Este posicionamento empurra o tratamento dos conflitos para o modelo de gestão, sem muito interesse na divisão ou mitigação das perdas que exijam recursos dispendiosos.

Um desdobramento dos conflitos identificados neste trabalho, em termos de estudos de caso, pode contribuir para identificar uma nova categoria que abarque mais adequadamente as possíveis situações das atuações e posicionamentos de atores. Isto contribuirá para a discussão de alternativas para classificação de conflitos socioambientais.

\section{REFERÊNCIAS}

Acselrad, H. (2002) Justiça ambiental e construção social do risco. Desenvolvimento e meio ambiente. (5), 49-60. Jan./jun.

. (2004) Movimiento de Justicia Ambiental: estrategia argumentativa e fourza simbólica.

In: Kiechmann, J. (Org.). Etica ecológica: propuesta para una reorientación. Montevideo: Nordam-Comunidad.

Alonso, Â. \& Costa, V. (2002a) Por uma sociologia dos conflitos ambientais no Brasil. In: Ecología política. Naturaleza, sociedad y utopía. Héctor Alimonda. Clacso.

. (2002b) Ciências sociais e meio ambiente no Brasil: um balanço bibliográfico. Rev. Bras. de Inf. Bibliográficas, Anpocs. (53), $2^{\circ}$ Semestre, 35-78.

. (2000) Por uma sociologia dos conflitos ambientais no Brasil. Anais. Encontro do Grupo Meio Ambiente e Desenvolvimento da Clacso, RJ, 22 e 23 de novembro.

Aquino, Y. (2012) Dilma: expansão elétrica será perseguida de forma planejada. EBC-Empresa Brasil de Comunicação, Site, em 17 out. 2012. Recuperado em: dezembro de 2012, de: http://www.ebc.com.br/2012/10/dilma-diz-que-governo-vai-perseguir-expansao-eletrica-de-formaplanejada-e-consistente>.

Barbanti Jr., O. (2002) Conflitos socioambientais: teorias e práticas. Encontro Associação Nacional de Pós-Graduação e Pesquisa em Ambiente e Sociedade, 1. Indaiatuba, SP. Novembro.

Barbieri, J. C. (2004) Educação e a gestão ambiental em cursos de graduação em administração: objetivos, desafios e propostas. Revista da Administração Pública, (38), fac. 6, 919-946. 
Benites, M. N. A., Maganhini, T. B. (2011) A participação popular como instrumento de proteção da Amazônia na criação das usinas hidrelétricas de Santo Antônio e Jirau. Observatório do Governo Eletrônico-UFSC. Outubro.

Bredariol, C. S. (2004) O aprendizado da negociação em conflitos ambientais. In: Encontro da Anppas, 2, Indaiatuba, SP, maio. Recuperado em: junho de 2011, de:

<http://www.anppas.org.br/encontro_anual/encontro2/GT/GT17/gt17_celso_bredariol.pdf>.

Creswell, J. (2010) Projeto de pesquisa: métodos qualitativo, quantitativo e misto. (3.ed.) Porto Alegre: Artemed e Boockman.

Fernandes, F., Santos, E. M. (2004) Reflexões sobre a história da matriz energética brasileira e sua importância para a definição de novas estratégias para o gás. Anais. Rio Oil \& Gas Expo and Conference 2004, realizada no período de 4 a 7 de outubro no Rio de Janeiro.

Flick, U. (2009) Introdução à pesquisa qualitativa. (3. ed.) Porto Alegre: Artmed.

Esteva, G. (1992) Development. In. Sachs, W. (org.) The development dictionary: a guide to knowledge and power. London: Zed Books.

Little, P. E. (2006) Ecologia política como etnografia: um guia teórico e metodológico. Horizontes Antropológicos, ano 12(25), jan-jun, 85-103.

. (2001) Os conflitos socioambientais: um campo de estudo e de ação política. In: Bartholo

Jr, R., Mota, C. R., Bernardo, M., Klink, C. A., Nascimento, E. P., Little, P. E., Drummond, J. A.,

Frota, I. \& Vianna, J. N. S.. Bursztyn, M. (org.). A difícil sustentabilidade. Rio de Janeiro:

Garamound, 107-122.

Mollinga, P. P. (2007) Water, politics and development: framing a political sociology of water resources management. Water Alternatives, 1, 7-23.

Muniz, L. M. (2010) Ecologia política: o campo de estudo dos conflitos socioambientais (sic). Revista Pós-Ciências Sociais,6(12). São Luiz: UFMA.

Nascimento, E. P. (2001) Conflitos da sociedade moderna: uma introdução conceitual. In: Bartholo Jr, R., Mota, C. R., Bernardo, M., Klink, C. A., Nascimento, E. P., Little, P. E., Drummond, J. A., Frota, I. \& Vianna, J. N. S.. Bursztyn, M. (org.). A difícil sustentabilidade. Rio de Janeiro: Garamound, 85-105.

Pereira, C. L. \& Nascimento, E. P. (2010) Luta em torno do parque estadual Cristalino (MT): Qual a natureza do conflito? Revista de Ciências Sociais, 41(2), jul/dez, 140-154.

Turton, A. R. et. al. (2007) Towards a model for ecosystem governance: an integrated water resource management example. Springer New York, LCC.

Vargas, G. M. (2007) Conflitos sociais e socioambientais: proposta de um marco teórico e metodológico. Sociedade \& Natureza. (19), Uberlândia/MG, 191-203.

Vergara, S.C. (2005) Paradigmas sociológicos e análise organizacional, segundo Gibson Burrel e Garet Morgan. Mim. 1991. Texto disponibilizado para a turma de Mestrado em Administração Pública da Ebape-FGV em março de 2005, quando ministrou a disciplina de Metodologia da Pesquisa Científica.

Zhouri, A. L. M., Oliveira, R. (2007). Desenvolvimento, conflitos sociais e violência no Brasil rural: o caso das usinas hidrelétricas. Ambiente \& Sociedade, 20(2). Campinas. jul-dez, 119-135.

Data da submissão: 27/06/2013

Data da publicação: 13/12/2013

Revista de Gestão Social e Ambiental - RGSA, São Paulo, v. 7, n. 3, p. 89-104, out./dez., 2013. 